\title{
Pacemaker dependence in patients with bifascicular block during acute anterior myocardial infarction
}

\author{
O EDHAG,$\star$ L BERGFELDT,$\star N$ EDVARDSSON,† S HOLMBERG, $†$ M ROSENQVIST, \\ H VALLIN *
}

From the ${ }^{\star}$ Cardiac Division of the Deparments of Internal Medicine, Huddinge Hospital, Karolinska Institute, Stockholm; and †Sahlgren's Hospital, University of Gothenburg, Sweden

SUMMARY Eleven patients with bifascicular block complicating anteroseptal acute myocardial infarction were studied to determine the effect of prophylactic permanent pacing; eight of them also had transient high grade atrioventricular block during the acute phase of the infarction. One month after the infarction an electrophysiological study was performed and a bradycardia indicating pacemaker implantied. All the patients were followed for two years. Six had bradycardia detected, two of whom did not have high grade atrioventricular block during the index infarction. Seven patients died, four of them suddenly. There was no correlation between the electrophysiological findings and subsequent development of bradycardia.

Thus pacemaker dependence seems to be common in patients with bifascicular block complicating acute myocardial infarction. Mortality is, however, also high in patients treated with pacemakers. Prospective studies to determine the predictive factors in those patients with an anterior acute myocardial infarction and who benefit from a combination of permanent pacemaker treatment and antiarrhythmic treatment are needed.

Patients who develop bundle branch block during the acute phase of an anterior myocardial infarction have a high incidence of late sudden death, which may be related to either ventricular tachycardia or the development of high grade atrioventricular block. ${ }^{1}$ In addition, patients with bundle branch block who have transient high grade atrioventricular block during the first days of infarction are considered to be subject to a high risk of sudden death after hospital discharge. ${ }^{2-4}$

The possible role of permanent pacemaker treatment in preventing sudden death in this high risk group has been suggested. ${ }^{56}$ The purpose of this study was to determine whether patients who developed bifascicular block during an acute anterior myocardial infarction became dependent on a pacemaker. Pacemaker dependence was assessed using a bradycardia indicating pacemaker. ${ }^{78}$

Requests for reprints to Dr O Edhag, Cardiac Division, Department of Internal Medicine, Huddinge Hospital, S-141 86 Huddinge, Sweden.

Accepted for publication 10 May 1984

\section{Patients and methods}

\section{DEFINITIONS}

The diagnosis of acute myocardial infarction was made when typical symptoms and enzyme abnomalities were present. The diagnosis of left bundle branch block and right bundle branch block was based on the usual criteria. ${ }^{9}$ Left anterior fascicular block was diagnosed in the presence of a frontal plane axis deviation to the left of $\geqslant-30^{\circ}$ and left posterior fascicular block in the presence of a frontal plane axis deviation to the right of $\geqslant+120^{\circ}$ in the absence of clinical evidence of right ventricular hypertrophy, pulmonary hypertension, or lateral wall infarction. Bifascicular block refers to left bundle branch block or to complete right bundle branch block with either left anterior or left posterior fascicular block. High grade atrioventricular block was defined as type II second degree block or third degree block.

\section{STUDY GROUP}

Eleven patients who developed bifascicular bundle branch block during the acute phase of an anterior or anteroseptal myocardial infarction were studied. 
Table 1 Patient characteristics

\begin{tabular}{|c|c|c|c|c|c|}
\hline \multirow[t]{2}{*}{ Case No } & \multirow{2}{*}{$\begin{array}{l}\text { Age (yr) } \\
\text { and sex }\end{array}$} & \multirow[t]{2}{*}{ Previous IHD } & \multicolumn{2}{|l|}{ Index infarction } & \multirow[t]{2}{*}{ Treatment } \\
\hline & & & Site & $\begin{array}{l}\text { Maximum serum } \\
\text { AST activity }(\mu K a t / l)\end{array}$ & \\
\hline $\begin{array}{l}1 \\
2 \\
3 \\
4 \\
5 \\
6 \\
7 \\
8 \\
9 \\
10 \\
11 \\
\text { Median }\end{array}$ & $\begin{array}{l}75 \mathrm{M} \\
68 \mathrm{M} \\
64 \mathrm{M} \\
71 \mathrm{M} \\
73 \mathrm{M} \\
73 \mathrm{M} \\
52 \mathrm{M} \\
55 \mathrm{M} \\
73 \mathrm{~F} \\
60 \mathrm{M} \\
77 \mathrm{M} \\
71\end{array}$ & $\begin{array}{l}\text { AMI } \\
\overline{A M I} \\
\overline{A M I} \\
\text { AMI, angina } \\
\text { AMI, angina } \\
\overline{\text { Angina }} \\
\text { AMI, angina } \\
\text { Angina }\end{array}$ & $\begin{array}{l}\text { Anteroseptal } \\
\text { Anteroseptal } \\
\text { Anteroseptal } \\
\text { Anterior } \\
\text { Anterior } \\
\text { Anterior } \\
\text { Anteroseptal } \\
\text { Anteroseptal } \\
\text { Anteroinferior } \\
\text { Anterior } \\
\text { Anterolateral }\end{array}$ & $\begin{array}{l}1 \cdot 3 \\
4 \cdot 8 \\
1.4 \\
2 \cdot 6 \\
4 \cdot 0 \\
\text { (LD increased) } \\
11 \cdot 0 \\
7 \cdot 5 \\
2 \cdot 2 \\
7 \cdot 0 \\
7 \cdot 9 \\
4.4\end{array}$ & $\begin{array}{l}\overline{-} \\
\bar{D} \text { igoxin and frusemide } \\
\text { Digoxin } \\
\text { Digoxin and frusemide } \\
\overline{-} \\
\overline{\text { Digoxin }} \\
\text { Digoxin } \\
\text { Digoxin } \\
\text { Digoxin }\end{array}$ \\
\hline
\end{tabular}

AST, aspartate aminotransferase; IHD, ischaemic heart disease; AMI, acute myocardial infarction.

$\mathrm{LD}$, lactate dehydrogenase.

Table 1 shows the clinical characteristics. The combination of right bundle branch block and left anterior fascicular block was recorded in five patients, right bundle branch block and left posterior fascicular block in one, and left bundle branch block in five. Transient high grade atrioventricular block was recorded during the first three days after admission in eight patients.

INTRACARDIAC ELECTROPHYSIOLOGICAL STUDY About one month after the acute infarction an electrophysiological study was performed. Either two or three pacing electrodes with an interelectrode distance of $1 \mathrm{~cm}$ were introduced percutaneously under local anaesthesia via a femoral vein and positioned high in the right atrium across the tricuspid valve and in some patients in the apex of the right ventricle. The intracardiac electrogram and surface leads I, II, and V1 were recorded on a Minogograph recorder with frequency limits of 50-700 $\mathrm{Hz}$ (Siemens-Elema, Sweden) at a paper speed of $100 \mathrm{~mm} / \mathrm{s}$. The atrioventricular conduction intervals were determined as the mean of at least three beats. The intranodal conduction time (AH) was determined from the most rapid phase of the intrinsicoid deflection of the $A$ wave recorded low in the right atrium to the first rapid phase of the $\mathrm{H}$ wave, and the infranodal conduction time (HV) from this point to earliest ventricular activity seen in any lead. The reference values of our laboratory for $\mathrm{AH}$ intervals are $55-110 \mathrm{~ms}$ and for $\mathrm{HV}$ interval 30 $55 \mathrm{ms.}^{10}$

\section{BRADYCARDIA INDICATING PACEMAKER}

This pulse generator was evolved from a conventional ventricular inhibited lithium powered pulse generator (Siemens-Elema). Two inhibition rates, one of 70 beats $/ \mathrm{min}$ and one of $30 \mathrm{beats} / \mathrm{min}$, are available each with a corresponding magnet rate of 60 and 100 beats/min respectively. If there is bradycardia of $<30$ beats/min the pulse generator automatically changes to the higher rates (stimulation rate 70 beats/min, test rate 100 beats/min), and this setting remains until the generator is reprogrammed by applying an external magnet.

The occurrence of bradycardia is recognised by the pacemaker when the spontaneous heart rate falls below 30 beats $/ \mathrm{min}$, and the device delivers three or more consecutive impulses or five or more impulses during any interval of $25 \mathrm{~s}$. If an episode of bradycardia has been recognised a subsequent electrocardiogram will show either a pacemaker induced rhythm with a rate of 70 beats/min or a spontaneous heart rhythm with a higher rate than this. In the latter situation the occurrence of bradycardia can be established by applying a magnet externally. A magnet induced rate of 100 beats/min indicates that an episode of bradycardia has occurred, whereas a rate of 60 beats/min shows the contrary. Further technical data on this pacemaker and the clinical results obtained with it have been reported elsewhere. ${ }^{45}$ To exclude intermittent undersensing or tachycardias related to bradycardia long term electrocardiography for 24 $48 \mathrm{~h}$ was performed after implantation of the bradycardia indicating pacemaker.

The investigation procedure was approved by the hospital ethical committees, and the patients gave informed consent.

\section{Results}

\section{CLINICAL COURSE AND MORTALITY}

After implantation of the bradycardia indicating pacemaker the patients were followed for up to two years (Table 2). One patient had a single attack of syncope and one several short episodes of dizziness. These symptoms were not associated with a bradycardia indication at subsequent follow up. One patient (case 2) had progressed to complete heart block at 
Table 2 Clinical course after implantation of a bradycardia indicating pacemaker, electrocardiographic data during the acute phase of the inde infarction, and electrophsyiological data one month after infarction

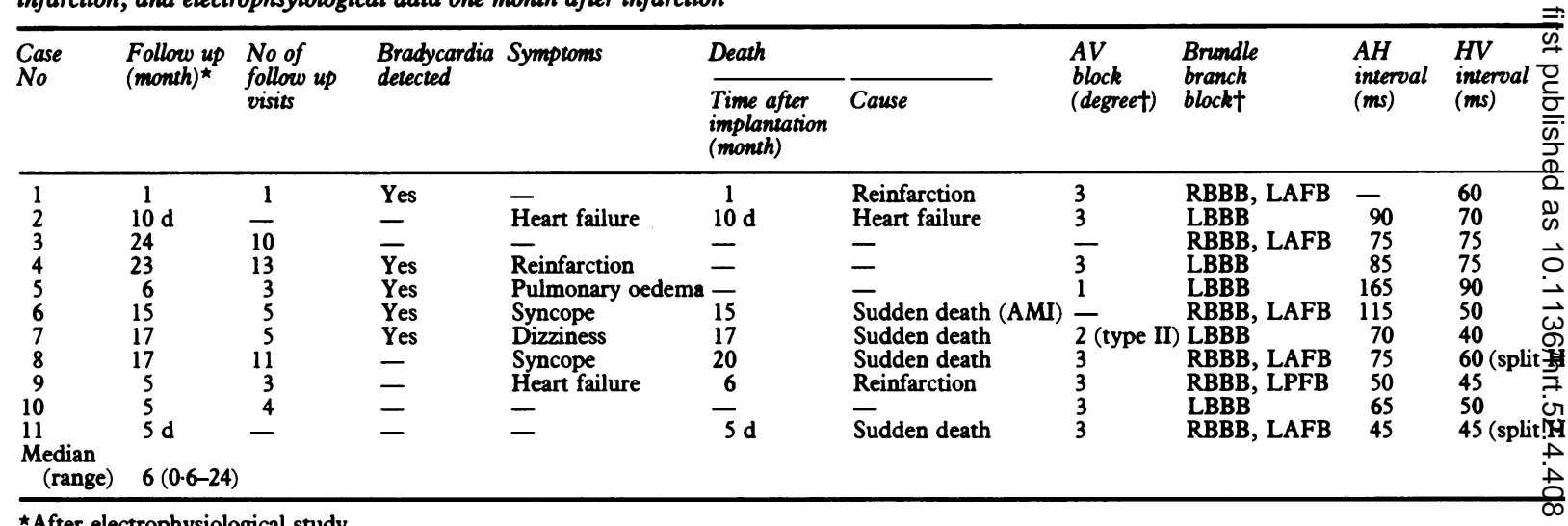

$\star$ After electrophysiological study.

†Highest recorded.

AV, atrioventricular; RBBB, right bundle branch block; LBBB, left bundle branch block; LAFB, left anterior fascicular block; LPFB, left posterior fascicu block.

routine follow up, and one had a reinfarction. Eight patients were treated for heart failure. Six had episodes of bradycardia detected by the pacemaker, one after 23 months (case 4). Two of the three patients without high grade atrioventricular block during the acute phase of their infarction had one or more episodes of bradycardia detected.

Seven patients died, four of them suddenly; three of the four and a further two had a reinfarction confirmed clinically or at necropsy. Three of the four who died suddenly had had episodes of bradycardia previously detected by the bradycardia indicating pacemaker before death.

\section{ELECTROPHYSIOLOGICAL DATA}

The HV interval was prolonged in six patients (Table 2). One patient with a prolonged and one with a normal HV interval had a split His. Four of the six patients with prolonged $\mathrm{HV}$ interval had transient high grade atrioventricular block during the acute phase of the infarction. Two patients with a normal HV interval had bradycardia detected during follow up.

\section{CORRELATION BETWEEN}

ELECTROPHYSIOLOGICAL AND CLINICAL

FINDINGS

The patient (case 8) with a split His and prolonged $\mathrm{HV}$ interval had had ventricular fibrillation during the index infarction, had an attack of syncope, and had bradycardia indicated during follow up. He had a reinfarction and died suddenly. The second patient with a split His also had a reinfarction and died suddenly. The only patient who had complete heart block recorded during follow up died of heart failure (case
2). Two of the patients with normal HV intervals died suddenly, one after a reinfarction. The electrophysiological study thus predicted neither episodes of bradycardia or syncope during follow up nor sudden death.

\section{Discussion}

One important finding arose from this study. Two patients (18\%) with bifascicular block complicating acute anteroseptal myocardial infarction-even without transient high grade atrioventricular block during the infarction-became pacemaker dependent during long term follow up. Furthermore, in this study electrophysiological tests before pacemaker implantation could not predict pacemaker dependence as confirmed by a bradycardia indicating pacemaker.

Patients with bundle branch block and transient high grade atrioventricular block during acute myocardial infarction are subject to an increased risk of late sudden death. ${ }^{24}$ The value of permanent cardiac pacing in this patient group is uncertain. The reasons for instantaneous death might be a fatal ventricular arrhythmia as well as development of complete heart block with ventricular standstill. The slow heart rate might in this context facilitate a malignant ventricular extrasystole. Ginks et al reported the long term prognosis after acute anterior myocardial infarction with transient high grade atrioventricular block. ${ }^{11}$ After recovery from infarction 17 patients with bifascicular block were followed for a mean period of 49 months. During follow up one patient developed complete heart block requiring permanent pacing and three patients died suddenly. These authors concluded that long term pacing was not 
justified in this group of patients if they are asymptomatic. Hauer et al, in a study in which 18 out of 42 patients survived and were discharged from hospital after an anteroseptal myocardial infarction complicated by bundle branch block, found a good prognosis during 14 months' follow up. ${ }^{12}$ The only patient who died did so during an aneurysmectomy. Their conclusion also was that prophylactic permanent pacing does not affect the prognosis of these patients.

Nimetz et al studied 13 discharged patients with an acute myocardial infarction complicated by bundle branch block and high grade atrioventricular block and found no difference in the incidence of sudden death compared with those without these complications during the same mean follow up period. ${ }^{3}$ In contrast to these reports, which do not support prophylactic permanent pacing as a lifesaving treatment in patients with bundle branch block complicating an acute myocardial infarction, there are several which draw the opposite conclusion.

In a series of 239 patients with bundle branch block complicating acute myocardial infarction and without second or third degree atrioventricular block Hindman and coworkers found an incidence of $13 \%$ of sudden death or high grade atrioventricular block during the first year of follow up. ${ }^{4}$ Atkins and coworkers reported late sudden death in five of six patients with acute myocardial infarction, right bundle branch block, and left axis deviation followed during an 11 month period. 5 All had transient complete heart block during the acute phase of the infarction. Four of the five deaths were sudden. They recommend permanent pacing if complete heart block develops, even though transient, in patients with acute myocardial infarction and also a combination of right bundle branch block and left axis deviation. Two of the three patients in our series without high grade atrioventricular block during the acute phase of the infarction had episodes of bradycardia indicated. Thus even patients without transient high grade atrioventricular block might sometimes be dependent on a pacemaker.

Hollander and coworkers in a review of published reports and from their own experience in 46 patients with anterior wall acute myocardial infarction and left bundle branch block considered it reasonable to treat these patients with a prophylactic pacemaker. ${ }^{13}$

The present series showed that a high proportion of the patients with bifascicular block complicating anterior acute myocardial infarction became pacemaker dependent. Despite prophylactic pacemaker treatment seven out of 11 patients died during the follow up period. Lie et al found a high incidence of ventricular fibrillation in patients with myocardial infarction complicated by bundle branch block. ${ }^{14}$ In accordance with this finding are the four patients who died suddenly in the present study.

The prognosis for the patients in the present study was poor despite their having had cardiac pacemakers implanted. The occurrence of bifascicular block in patients with an anterior or anteroseptal myocardial infarction indicates advanced myocardial damage and that progression of the coronary heart disease-even if minor-might within a limited time be fatal. What proportion of the fatal arrhythmias in these patients were due to ventricular tachycardia or ventricular standstill is unknown. A third possiblity is a bradycardia facilitating ventricular tachycardia or fibrillation. If an episode of ventricular tachycardia occurs in a patient who has had a bradycardia indicating pacemaker implanted, as described above, the bradycardia circuit will not be activated. Moreover, a transient episode of venuricular fibrillation will not be distinguished from that of asystole by the bradycardia circuit. The symptoms during the episode will, however, distinguish between these two arrhythmias. During bradycardia with three consecutive stimulations at a rate of 30 beats/min, lightheadedness will occur (if any symptoms occur at all) whereas during ventricular fibrillation complete syncope will most probably occur.

Ginks et al did not find HV prolongation to be a predictor of sudden death in eight of 25 patients with acute anterior infarction and recurrent complete heart block. ${ }^{11}$ Nor in the present study were electrophysiological measurements of any predictive value in detecting bradycardia or determining mortality.

To achieve the maximum therapeutic effect a combination of prophylactic pacemaker treatment and medication with antiarrhythmic drugs is probably necessary. There is, however, probably a high risk group who do not benefit from any treatment because of advanced ischaemic heart disease and perhaps also a low risk group who have an uneventful couse even without treatment. Further prospective studies are needed to identify the predictive factors of patients who will benefit from one or a combination of these treatments. The bradycardia indicating pacemaker is valuable in such an evaluation.

\section{References}

1 Fisch GR, Zipes DP, Fisch C. Bundle branch block and sudden death. Prog Cardiooasc Dis 1980; 23: 187-224.

2 Waugh RA, Wagner GS, Haney TL, Rosati RA, Morris Jr JJ. Immediate and remote prognostic significance of fascicular block during acute myocardial infarction. Circulation 1973; 47: 765-75.

3 Nimetz AA, Schubrools Jr SJ, Hutter Jr AM, De Sanctis RW. The significance of bundle branch block during acute myocardial infarction. Am Heart $\mathcal{F}$ 1975; 90: 439 44.

4 Hindman MC, Wagner GS, JaRo $M$, et al. The clinical 
significance of bundle branch block and myocardial infarction. 1. Clinical charactertistics, hospital mortality, and one-year follow up. Circulation 1978; 58: 679-88.

5 Atkins JM, Leskin SJ, Blomqvist G, Mullins CB. Ventricular conduction blocks and sudden death in acute myocardial infarction. Potential indications for pacing. $N$ Engl f Med 1973; 288: 281-4.

6 Hindman MC, Wagner GS, JaRo M, et al. The clinical significance of bundle branch block complicating acute myocardial infarction. 2. Indications for temporary and permanent pacemaker insertion. Circulation 1978; 58: 689-99.

7 Edhag KO, Elmqvist H, Vallin HO. An implantable pulse generator indicating asystole or extreme bradycardia. PACE 1983; 6: 166-70.

8 Rosenqvist M, Edhag KO, Vallin HO. Clinical experience with a bradycardia indicating pacemaker. $P A C E$ 1983; 6: 515-24.

9 Goldman MJ. Principles of clinical electrocardiography. 7th ed. Altos, California: Lange, 1970.
10 Vallin HO. Autonomous influence on sinus node and AV node function in the elderly without significant heart disease: assessment with electrophysiological and autonomic tests. Cardiovasc Res 1980; 14: 206-16.

11 Ginks WR, Sutton R, Winston OH, Leatham A. Longterm prognosis after acute antrior infarction with atrioventricular block. $\mathrm{Br}$ Heart $\mathcal{F}$ 1977; 39: 186-9.

12 Hauer RNW, Lie KI, Liem KL, Durrer D. Long-term prognosis in patients with bundle branch block complicating acute anteroseptal infarction. Am $\mathcal{f}$ Cardiol 1982; 49: 1581-5.

13 Hollander G, Nadimiati V, Lichstein E, Greengart A, Sanders $M$. Bundle branch block in acute myocardial infarction. Am Heart $\mathcal{F}$ 1983; 105: 738-43.

14 Lie KI, Liem KL, Schuilenburg RM, David GK, Durrer D. Early identification of patients developing late inhospital ventricular fibrillation after discharge from the coronary care unit. A $5 \frac{1}{2} 2$ year retrospective and prospective study in 1897 patients. Am $\mathcal{F}$ Cardiol 1978; 41: 674-7. 